\title{
COMMENT
}

\section{Commentary on primary productivity and nutrient limitation in the Neuse River Estuary, North Carolina, USA}

\author{
Michael A. Mallin ${ }^{1}$, Hans W. Paerl ${ }^{2}$ \\ ${ }^{1}$ Department of Biological Sciences, University of North Carolina at Wilmington, Wilmington, North Carolina 28403, USA \\ ${ }^{2}$ University of North Carolina at Chapel Hill, Institute of Marine Sciences, Morehead City, North Carolina 28557, USA
}

A recent paper by Boyer et al. (1993) described primary productivity analyses conducted in the Neuse River and estuary during 1985-88. The authors cited our earlier paper (Mallin et al. 1991) and, unfortunately, made a number of misrepresentations and omissions regarding our work. They implied that we greatly underestimated estuarine primary production and criticized our productivity methodology. Further, they ignored nutrient limitation as a critical factor in Neuse Estuary productivity dynamics and suggested that light limitation is more important. The purpose of this 'Comment' is to correct these misunderstandings.

Our field collections involved sampling estuarine water in large (25 l) carboys, returning them to the laboratory in the afternoon or evening, and holding the carboys in an outdoor circulating tank at ambient sea temperatures overnight for productivity analysis the next day (Mallin et al. 1991, Mallin \& Paerl 1992) Boyer et al. (p. 295) stated that [we] 'may have inadvertently promoted nutrient limitation and lowered our estimates of production'. Boyer et al. failed to mention that we had pre-tested this procedure several times and found no significant change in productivity, provided that analyses were conducted within $24 \mathrm{~h}$, a detail clearly explained in our methods (e.g. Mallin et al. 1991). They also speculated that the length of our incubations ( 3.5 to $4.0 \mathrm{~h}$ centered around noon) may have promoted nutrient limitation and lowered our productivity estimates. The incubation periods followed standard protocol (Vollenweider 1974, Wetzel \& Likens 1991). Further, we pre-tested Neuse Estuary water by incubating samples at light-saturating conditions and found linear ${ }^{14} \mathrm{C}$ uptake for $4 \mathrm{~h}\left(\mathrm{r}^{2}=0.98\right.$, unpubl. data).

Boyer et al. reported mean annual primary production for the Neuse estuarine system at $456 \mathrm{~g} \mathrm{C} \mathrm{m}^{-2}$.
They attributed an annual production value of $200 \mathrm{~g} \mathrm{C}$ $\mathrm{m}^{-2}$ to Mallin et al. (1991), which they estimated on the basis of the 7 mo of data that were available from our 1988 research. The only annual value we actually provided in Mallin et al. (1991) was $343 \mathrm{~g} \mathrm{C} \mathrm{m}^{-2}$ for 1989 , and our one other published annual estimate from multiple stations was $297 \mathrm{~g} \mathrm{C} \mathrm{m}^{-2}$ for 1990 (Paerl et al. 1990). Boyer et al. neglected to cite either of these published estimates. They did point out that greater productivity in their upstream stations could account for some of the discrepancy between their values and their estimate from our 1988 data; we agree with this general concept, and likewise have often found higher productivity at upstream stations (Paerl 1987, Mallin \& Paerl unpubl.).

Boyer et al, then speculated on our considerable methodological differences as a cause of the productivity differences between our studies. The Neuse Estuary is a well-mixed, moderately turbid system that provides constantly-changing irradiance levels to the phytoplankton. Our method utilized a light-field simulator wherein incubations were conducted in outdoor tanks under a rotating set of neutral-density screens that spanned a range of light intensities from open sunlight to near darkness (Mallin \& Paerl 1992). These incubations were designed to incorporate and integrate mixing-induced, as well as cloud-induced, irradiance variations into the ${ }^{14} \mathrm{C}$ uptake process itself. Thus, with our incubation conditions we attempted to simulate the changing light field of the estuary. In contrast, Boyer et al. determined monthly $P_{\max }$ values from samples incubated at $393 \mu \mathrm{E} \mathrm{m}^{-2} \mathrm{~s}^{-1}$ under static artificial irradiance with $\alpha_{\mathrm{f}}$ values ( $\alpha_{\mathrm{f}}=$ the initial slope of the $P$-I curve) that were computed quarterly (incubations over a range from 0 to $393 \mu \mathrm{E} \mathrm{m}^{-2} \mathrm{~s}^{-1}$ ). To obtain hourly productivity values, their $P_{\max }$ and $\alpha_{1}$ values were then 
applied in an equation with the light attenuation coefficient $k$ and incident irradiance $I_{0}$ and using hourly $I_{0}$ integrated from a pyranometer. Their method assumed constant $\alpha_{f}$ values throughout the day, and they used extrapolated $\alpha_{f}$ values for samples collected between quarterly dates.

Methodological differences aside, the largest factor contributing to the discrepancy in our annual production estimates can be viewed more fundamentally. Boyer et al. failed to consider depth differences in their comparison of our areal production estimates. Their nearest station (A) yielded $374 \mathrm{~g} \mathrm{C} \mathrm{m}^{-2}$ in a $4.3 \mathrm{~m}$ depth water column. Our nearest station (Channel Marker 6) was $3.3 \mathrm{~m}$ in depth, and our mean transect depth was $3.8 \mathrm{~m}$. Normalizing their 1988 result to a $3.3 \mathrm{~m}$ depth water column yields production of $287 \mathrm{~g} \mathrm{C} \mathrm{m}^{-2}$; similarly considered, a water column $3.8 \mathrm{~m}$ in depth yields $330 \mathrm{~g} \mathrm{C} \mathrm{m}^{-2}$. When compared with our 1989 and 1990 published transect values of 343 and $297 \mathrm{~g} \mathrm{C} \mathrm{m}^{-2}$. respectively, the differences were not so great for the lower estuary, after all. Our more recent work indicates that annual volumetric production may actually vary considerably from year to year (i.e. differences of 60 to $120 \mathrm{~g} \mathrm{C} \mathrm{m}^{-3}$ ), depending on river flow rates and nitrate loading to the lower estuary (Mallin et al. 1993).

Boyer et al. (p. 295) implied that we relied solely on direct positive correlations to support our hypothesis of $\mathrm{N}$-limitation in the Neuse Estuary. At no time did we state or imply that assumption in Mallin et al. (1991). What was highly germane to the subject (and what Boyer et al. neglected to cite), are two of our other publications (Paerl et al. 1990, Rudek et al. 1991) which presented the results of 3 yr of nutrient limitation bioassays. These data demonstrated that the mesohaline section of the Neuse was N-limited year-round, with co-limitation by $\mathrm{P}$ during spring. Additional bioassays have confirmed $N$-limitation under both static and variable irradiance conditions (Bates, Paerl \& Mallin unpubl.).

In our later paper (Mallin et al. 1993) we analyzed 42 mo of data from our $3.3 \mathrm{~m}$ depth reference station in the lower Neuse. This analysis demonstrated that hydrological delivery of nitrate substantially influences estuarine primary productivity, but it also emphasized the importance of a lag time in the transport of nitrate from upstream sources and subsequent stimulation of productivity downstream. In fact, this lag time may be seen graphically in Boyer et al. (Fig. 3) where the chlorophyll blooms follow salinity decreases (and subsequent nitrate delivery)

The riverine portion of the Neuse (Boyer et al. Stns F and $\mathrm{G}$ ) is nutrient-rich and turbid (Paerl 1987, Paerl \&
Bowles 1987, Christian et al. 1991); hence, light limitation may, at times, be operative in that region, as Boyer et al. implied. In contrast, our experimental work has demonstrated that under moderately turbid conditions (such as in the mesohaline estuary), normal watercolumn mixing can overcome light-limitation effects (Mallin \& Paerl 1992). Moreover, nitrate is usually stripped out of the water column by phytoplankton uptake in the oligohaline portion, so that little remains for uptake in the mesohaline estuary (Christian et al. 1991). Ambient nitrate concentrations, coupled with our experimental evidence, make a strong case for $\mathrm{N}$ limitation in the mesohaline estuary. Since, as Boyer et al. (p. 295) noted, 75\% of the system's primary production occurs in the mesohaline section, the importance of nitrogen limitation to this estuary should not be under-emphasized.

\section{LITERATURE CITED}

Boyer, J. N., Christian, R. R., Stanley, D. W. (1993). Patterns of phytoplankton primary productivity in the Neuse River estuary, North Carolina, USA. Mar. Ecol. Prog. Ser. 97: $287-297$

Christian, R. R., Boyer, J. N., Stanley, D. W. (1991). Multi-year distribution patterns of nutrients within the Neuse River Estuary, North Carolina. Mar. Ecol. Prog. Ser. 71: 259-274

Mallin, M. A., Paerl, H. W. (1992). Effects of variable irradiance on phytoplankton productivity in shallow estuaries Limnol. Oceanogr. 37: 54-62

Mallin, M. A., Paerl, H. W., Rudek, J. (1991). Seasonal phytoplankton composition, productivity and biomass in the Neuse River Estuary, North Carolina. Estuar. coast. Shelf Sci. 32: 609-623

Mallin, M. A., Paerl, H. W., Rudek, J., Bates, P. W. (1993). Regulation of estuarine primary production by watershed rainfall and river flow. Mar. Ecol. Prog. Ser. 93: 199-203

Paerl, H. W. (1987). Dynamics of blue-green algal (Microcystis aeruginosa) blooms in the lower Neuse River, North Carolina: causative factors and potential controls. University of North Carolina Water Resources Research Institute, Report No. 229, Raleigh, N.C.

Paerl, H. W., Bowles, N. D. (1987). Dilution bioassays: their application to assessments of nutrient limitation in hyper. eutrophic waters. Hydrobiologia 146: 265-273

Paerl, H. W., Mallin, M. A., Rudek, J., Bates, P. W. (1990). The potential for eutrophication and nuisance algal blooms in the lower Neuse River Estuary. Albemarle-Pamlico Estuarine Study Project No. 90-15, North Carolina Dept of Natural Resources and Community Development, Raleigh

Rudek, J., Paerl, H. W. Mallin, M. A., Bates, P. W. (1991). Seasonal and hydrological control of phytoplankton nutrient limitation in the lower Neuse River Estuary, North Carolina. Mar. Ecol. Prog. Ser. 75: 133-142

Vollenweider, R. A. (1974). A manual on methods for measuring primary production in aquatic environments. IBP Handbook No. 12, Blackwell Scientific, Oxford

Wetzel, R. W., Likens, G. E. (1991). Limnological. analysis. Springer-Verlag, New York 